\title{
Analysis of Intensified Sustainable Schemes for Biobutanol Purification
}

Segovia-Hernández, Juan Gabriel; Sánchez-Ramírez, Eduardo; Alcocer-García, Heriberto; QuírozRamírez, Juan José; Udugama, Isuru A.; Mansouri, Seyed Soheil

\section{Published in:}

Chemical Engineering and Processing

Link to article, DOI:

10.1016/j.cep.2019.107737

Publication date:

2020

Document Version

Peer reviewed version

Link back to DTU Orbit

Citation (APA):

Segovia-Hernández, J. G., Sánchez-Ramírez, E., Alcocer-García, H., Quíroz-Ramírez, J. J., Udugama, I. A., \& Mansouri, S. S. (2020). Analysis of Intensified Sustainable Schemes for Biobutanol Purification. Chemical

Engineering and Processing, 147, [107737]. https://doi.org/10.1016/j.cep.2019.107737

\section{General rights}

Copyright and moral rights for the publications made accessible in the public portal are retained by the authors and/or other copyright owners and it is a condition of accessing publications that users recognise and abide by the legal requirements associated with these rights.

- Users may download and print one copy of any publication from the public portal for the purpose of private study or research.

- You may not further distribute the material or use it for any profit-making activity or commercial gain

- You may freely distribute the URL identifying the publication in the public portal 


\section{Journal Pre-proof}

Analysis of Intensified Sustainable Schemes for Biobutanol Purification

Juan Gabriel Segovia-Hernández, Eduardo Sánchez-Ramírez, Heriberto Alcocer-García, Juan José Quíroz-Ramírez, Isuru A. Udugama, Seyed Soheil Mansouri

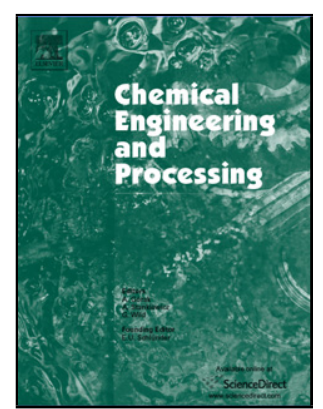

PII: $\quad$ S0255-2701(19)30638-5

DOI: $\quad$ https://doi.org/10.1016/j.cep.2019.107737

Reference: $\quad$ CEP 107737

To appear in: $\quad$ Chemical Engineering and Processing - Process Intensification

Received Date: $\quad 27$ May 2019

Revised Date: $\quad 6$ November 2019

Accepted Date: $\quad 7$ November 2019

Please cite this article as: Segovia-Hernández JG, Sánchez-Ramírez E, Alcocer-García H, Quíroz-Ramírez JJ, Udugama IA, Mansouri SS, Analysis of Intensified Sustainable Schemes for Biobutanol Purification, Chemical Engineering and Processing - Process Intensification (2019), doi: https://doi.org/10.1016/j.cep.2019.107737

This is a PDF file of an article that has undergone enhancements after acceptance, such as the addition of a cover page and metadata, and formatting for readability, but it is not yet the definitive version of record. This version will undergo additional copyediting, typesetting and review before it is published in its final form, but we are providing this version to give early visibility of the article. Please note that, during the production process, errors may be discovered which could affect the content, and all legal disclaimers that apply to the journal pertain.

(c) 2019 Published by Elsevier. 


\section{Analysis of Intensified Sustainable Schemes for Biobutanol Purification}

Juan Gabriel Segovia-Hernández ${ }^{\mathrm{a},}$, Eduardo Sánchez-Ramírez ${ }^{\mathrm{a}}$, Heriberto Alcocer-García ${ }^{\mathrm{a}}$, Juan José Quíroz-Ramírez ${ }^{\mathrm{b}}$, Isuru A. Udugama ${ }^{\mathrm{c}}$, Seyed Soheil Mansouri ${ }^{\mathrm{c}}$

${ }^{a}$ Universidad de Guanajuato, Campus Guanajuato, División de Ciencias Naturales y Exactas, Departamento de Ingeniería Química, Noria Alta S/N, Gto., México 36050.

${ }^{\text {b} C e n t r o ~ d e ~ I n n o v a c i o ́ n ~ A p l i c a d a ~ e n ~ T e c n o l o g i ́ a s ~(C I A T E C), ~ O m e g a ~ 201, ~ I n d u s t r i a l ~ D e l t a, ~}$ 37545 León, Gto.

'Process and Systems Engineering Centre, Department of Chemical and Biochemical Engineering, Technical University of Denmark, Søltofts Plads, Building 229, DK-2800 Kongens Lyngby, Denmark

*Author to whom all correspondence should be addressed, e-mail: gsegovia@ugto.mx, phone: (52) 4737320006 ext. 1407

\section{Graphical abstract}



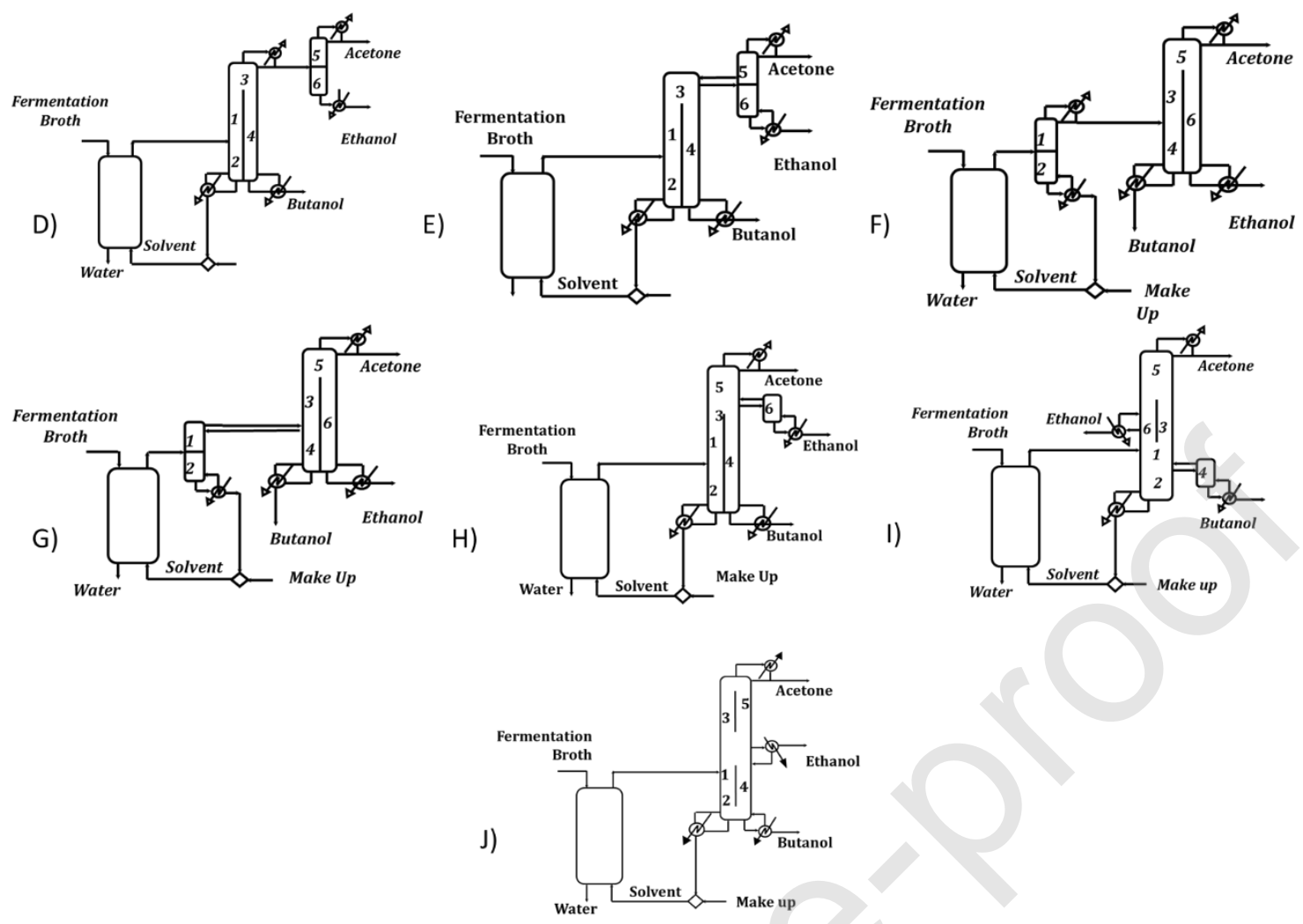

\section{Highlights}

- Butanol is an alternative fuel with characteristics competitive to petroleum-based fuels.

- Recovery of butanol by distillation is an energy intensive process.

- If the process is highly intensified, the sustainability and the inherent safety are improved.

\section{Abstract}

Butanol is an alternative fuel with characteristics competitive to petroleum-based fuels.

Compared with ethanol, butanol shows less miscibility, flammability, and corrosion; while potentially replacing gasoline in car engines without modifications. However, the production cost of butanol from renewables feedstock, i.e. bio-butanol (which also contains 
acetone and ethanol) through fermentation remains high. This is mainly due to the low yield of butanol in fermentation. The conventional recovery of butanol by distillation is an energy-intensive operation that has greatly restricted the industrial production of biobutanol. This work studies ten hybrid and intensified configurations, based on the liquidliquid extraction and dividing wall columns, to purify the butanol to the fuel grade. The study analyzes sustainability based on green metrics, including the inherent safety and control properties using singular value decomposition analysis. The results indicate that as long as the process is highly intensified, the sustainability and the inherent safety are improved and not necessarily the control properties. This is primarily due to the loss in the degrees of freedom in intensified processes.

Keywords: Dividing wall columns, hybrid process, inherent safety, sustainability, control properties.

\section{Introduction}

Due to the increase in oil prices in recent years and to the generation of a large dependence on fossil fuels, a great interest in the production of biofuels through the fermentation of agricultural biomass and organic solid waste is created. Butanol is one of those fuels that can be produced from agricultural crops such as corn and molasses using C. acetobutylicum or $C$. beijerinckii [1]. The advantage of using these and some other bacteria is that they can use both lignocellulosic, hexose and pentose, hydrolyzed sugars as well as non-hydrolyzed sugars [2]. Unlike ethanol and other fuels derived from fermentation, butanol has some advantageous properties: a) the energy content of Butanol is $30 \%$ more than ethanol and is closer to gasoline; b) its low vapor pressure facilitates its application in existing gasoline 
pipelines; c) it is less soluble in water; d) it is less volatile; e) less toxic; f) less flammable and g) can be mixed with gasoline in any proportion [3].

The production of butanol by fermentation is one of the oldest processes used for commercial production, the first report of a biological route for butanol synthesis is from Louis Pateuri in 1861 [4] at Strane \& Graham Ltd in UK. In collaboration with William Perkin from Manchester University, they identified C. Acetobutylicum which was able to produce large amounts of acetone and butanol. In subsequent years, during World War I, this fermentation process played an important role since acetone was needed for the production of the smokeless gunpowder cordite [5]. During 1940's, approximately $66 \%$ of the total butanol and $10 \%$ of the total acetone were obtained by yeast fermentation [4]. During World War II, the commercial interest focused into acetone; however, because of the petrochemical route research, the production of both components was left aside. Nowadays, the yield in the production of butanol from biomass is very low, which makes the production of butanol by fermentation economically infeasible. The concentration of butanol produced in the batch fermenter is quite low $(20 \mathrm{~g} / \mathrm{L})$ due to toxicity problems and metabolic pathways. In addition, depending on the culture and medium, many other compounds may be produced, e.g. acetone and ethanol. All of them must be removed from the mixture coming from the fermenter in downstream purification. The economics of the process could be improved if butanol is produced from agricultural residues and the product could be recovered using energy-efficient separation techniques $[1,3,6]$.

The main drawback of the fermentation processes is that products are often rather dilute and they require highly energy intensive separation and purification stages, which represent more than 50\% of the total annualized costs (TAC)[7]. In this regard, taking advantage of process intensification principles, a combination of liquid-liquid extraction with advanced 
distillation technologies could be used to increase the concentration of the diluted stream and then purify the main product. For example, Sánchez-Ramírez et al [8] have analyzed and compared four different possible processes for the purification of butanol production based on conventional distillation. The results indicated that the process consisting of a liquid-liquid extraction column followed by distillation turned out to be a cost-effective design from an economic point of view. Dividing wall column (DWC) is a good example of distillation separation units with heat integration and quite an established industrial application due to its high thermodynamic separation efficiency. In spite of the advantages of DWC from an operational and capital cost expenditure perspective, its industrial application only began three decades ago. The world's first DWC was installed and operated by BASF in 1985. Moreover, understanding of control and operability issues has improved greatly [9-11]. Since then, many DWCs have been established worldwide, such as in Europe, South Africa, and the US. Amminudin et al [12] noted the industrial acceptance and commercialization of DWC by organizations such as BASF AG, M.W. Kellogg (together with BP, later known as BP Amoco), and Sumitomo Heavy Industries Co. together with Kyowa Yuka. Linde AG constructed the world's largest DWC for Sasol, an estimated $107 \mathrm{~m}$ tall, and $5 \mathrm{~m}$ in diameter. Hence, there are better prospects for DWC in the near future, and it might become a standard distillation configuration in chemical process industries in the next 50 years [13]. The increasing energy cost and the concern about global warming in recent years have made the DWC an attractive alternative for reducing carbon footprint of separations in chemical process industries. Regarding the number and variety of industrial applications, DWC can already be considered as a distillation process intensification success story. Many applications are known today, mainly concerning separations of ternary mixtures. The development and implementation 
efforts focus nowadays on the separation of more than three components or applications of extractive, azeotropic and reactive distillation in a DWC [14]. Being a genuine representative of substantial distilling, making slowly inroad into the applications dominated by tray columns, DWC will certainly develop into a standard type of distillation column in the near future [15].

Among the distillation technologies, the dividing wall column (DWC) is a promising alternative for separating and purifying the effluents produced by fermentation [16]. Okoli and Adams [17] studied the separation of butanol in a quaternary DWC, by minimizing TAC, as an objective function. Errico et al. [18] explored DWC as a promising intensified distillation alternative in combination with liquid-liquid extraction. Their results indicated a reduction of $22 \%$ and $18 \%$ in the economy and the environmental indices, respectively. Considering the control properties of the process for the purification of butanol, Luyben [19] carried out a first-pass analysis. His work studies the control of the azeotropic butanol/water distillation system and develops a control structure that is capable of eliminating very large perturbations. The control system is robust and applicable to systems that are designed for a wide range of feed compositions. The control properties of four different processes (based on conventional distillation), for the purification of butanol, acetone, ethanol, and water, are analyzed in the work of Angelina-Martínez et al. [20] using the singular value decomposition method. The results indicated that the scheme where only the butanol stream is purified, and ethanol and acetone leave the purification process mixed with water and traces of butanol, has best control properties. Sánchez-Ramírez et al. [21], used both open-loop and closed-loop analysis and obtained the dynamic properties of several hybrid processes to separate an effluent produced by fermentation. This work verifies that it is possible to control all the schemes under open-loop and closed-loop 
methodologies and it was clear that the elimination of a section in the column improved the control properties.

Today, there are huge global environmental concerns, including energy and fuels, food, transport, use of water, pollution and ecological destruction. The current and future objectives of process engineers are not only to maintain and reduce the cost of the products, but also to simultaneously reduce the impact on the environment and human health. The growing concern for the environment, the increase of strict standards for the release of chemicals into the environment and economic competitiveness have led to more environmentally friendly approaches that have resulted in greater prevention of pollution through the reduction of waste and the maximization of efficiency[22]. Green process engineering is an important tool that could make significant contributions in driving the sustainability of hazardous and waste processes to the benefit of the economy, the environment, and society. Some examples of current and future applications of ecological process engineering have been presented, particularly in the areas of biofuels [23]. Keeping in mind that an intensified process is the one that reduces the size of equipment, increased performance of the process, reduced equipment inventory, diminishment in using utilities and raw materials, and increased efficiency of process equipment [24]. Process intensification seems a natural alternative for cover all listed necessities of a green process. Even process intensification was initially considered as an alternative for reducing cost since the three kinds of improvements is oriented to the integration of operation, integration of functions and integration of phenomena [25]; all intensified alternatives seem also to have many other characteristics if the goal is to obtain a green process.

Ramshaw [26] showed the potential of many intensified process at the light of a framework of green processes, however, the numerical evaluation of their proposal ware not evaluated. 
In the same sense, Ramshaw [26] concludes that if the process intensification is effectively implemented, it will lead to improvements in environmental acceptability, energy efficiency, intrinsic safety, and capital cost.

The importance of considering sustainability issues early in the design of the intensified process can help to differentiate between processes that are easy and process that is difficult to operate. According to Jiménez-González et al. [23] should consider incorporating "green metrics" when designing an intensified process towards the broader goal of environmental sustainability. Among those green metrics should be highlighted the aspects of environmental, health, safety and process control. Green Chemistry Principle \#11 expresses a desire to have real-time process analysis and monitoring in place. The aim of this principle is simple enough — to prevent waste and safety issues by identifying process excursions as they occur. By doing so, there may be sufficient time to modify process parameters such that the excursion may be reversed and there is no subsequent impact on safety and the final product quality. Real-time analysis and process control are necessary to carry out this action. In the same sense, the intensification of processes, associated with the reduction of the number of equipment and change in the system topology of the system, can also modify control properties and dynamic performance compared to non-intensified systems [24,27-29]. Contrary to the conventional distillation process, the "greenness", inherent safety and dynamic of the complex distillation columns, based in DWC have not been explored in the published literature.

With this in mind, the aim of this work is to evaluate if some intensified process could cover the necessities previously proposed for a green process. Moreover, the authors consider quite interesting to evaluate the greenness of a downstream process to purify a 
biofuel; additionally, if possess the characteristics to fit in a layout evaluated under the light of a sustainable and green process.

As far as the authors are aware, no study has been carried out on the sustainability and inherent safety of the purification section, based on the liquid-liquid extraction and DWC, of the butanol, acetone, ethanol, and water mixture. In this work, we study the configurations proposed by Errico et al. [18] to analyze their sustainability, based on the green metrics proposed by Jiménez-González et al. [23]. Their inherent security is complemented with the analysis of open-loop control properties with the technique of singular value decomposition. Jimenez-Gonzalez et al. [23] highlights as main metrics to define a process as sustainable both the control of the process as well as the inherent safety of it. The primary need for this pair of analysis is the desire to have real-time on-site monitoring. Therefore, process waste and the safety risks associated with it can be minimized. Additionally, having an adequate control strategy, there is enough time to modify the process parameters, avoiding the subsequent impact on safety and the final product.

\section{Analyzed configurations and case study}

Previously, Errico et al. [18] presented a complete synthesis methodology to generate separation alternatives to purify biobutanol. In brief, the methodology starts from a hybrid process design with a liquid-liquid extractive column and a set of three conventional distillation columns. Considering a base case, Errico et al. [18] applied a systematic methodology to produce several alternatives, liquid-liquid extraction-assisted conventional 
DWC configurations, and liquid-liquid extraction-assisted nonconventional DWC configurations. All those alternatives were designed considering the NRTL-HOC as a thermodynamic model to describe phase equilibrium. Note Figure 1 shows experimental composition of the binary system n-butanol / water obtained in the temperature range 323$393 \mathrm{~K}$ and pressures between 13.4 and $267 \mathrm{kPa}$ [30], and the data predicted by the NRTL model with default Aspen Plus binary interaction parameters. Additionally, previous works have reported a relatively good accuracy for predicting the interactions between the components [31-34]. The feedstream considered by Errico et al. [18] is presented in Table 1, and all schemes were modeled using Aspen Plus V 8.8.

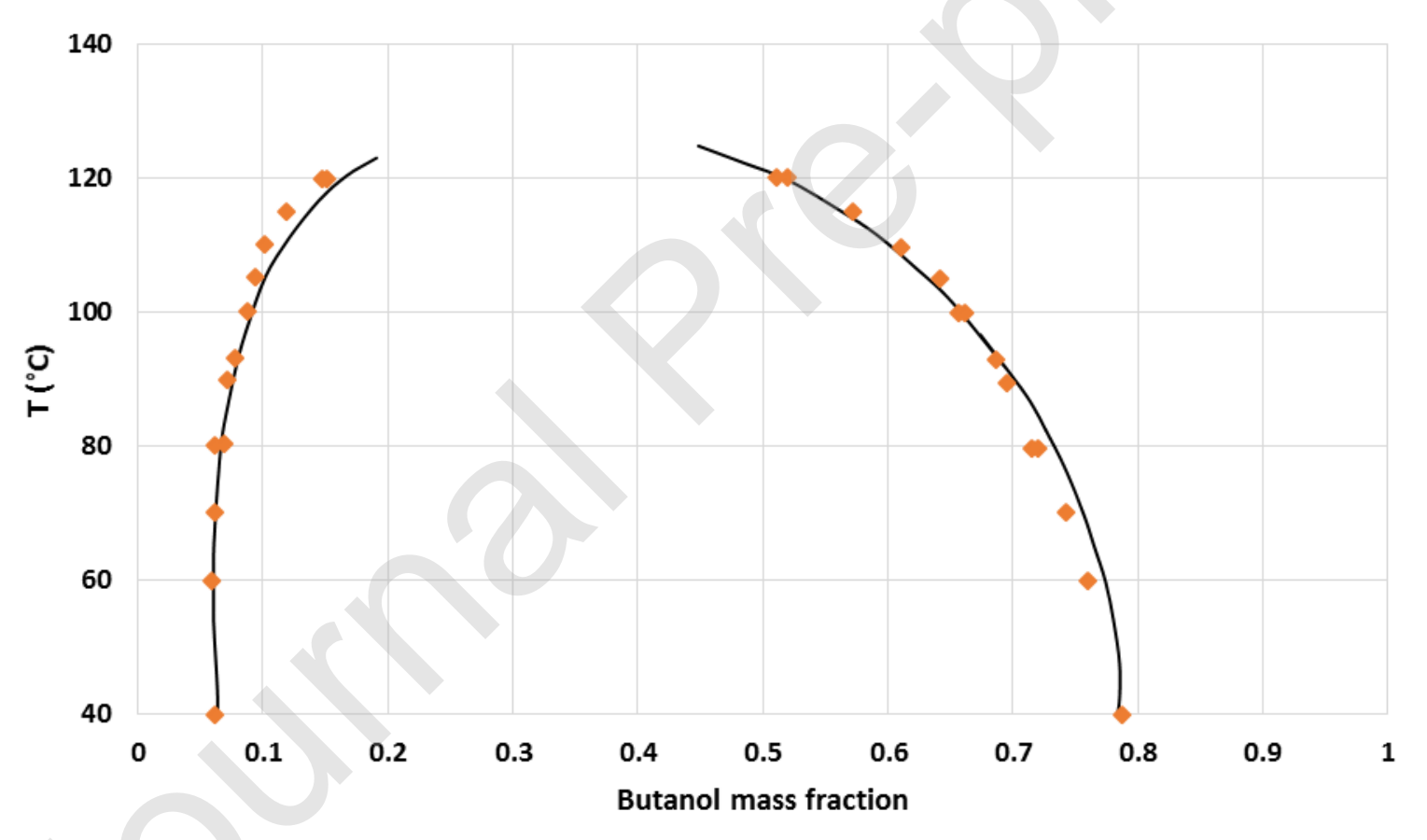

Figure 1. Comparison between LLE predicted by NRTL model (line) and experimental data [30]

The synthesis methodology was based on the inclusion of thermal couplings and both movement and elimination of a column section. All the generated alternatives were 
evaluated and optimized by means of a robust optimization algorithm, differential evolution with tabu list (DETL), evaluating the total annual cost and the eco-indicator 99 [35] as economic and environmental performance indices. Thereby, Errico et al. [18] reported a set of ten hybrid designs which may perform the Acetone-Butanol-Ethanol (ABE) separation with relatively good economic and environmental indexes.

The inherent risk (measured by the individual risk), and a selection of green metrics proposed by Jimenez-Gonzalez et al. [23], and the dynamic behavior are evaluated for those designs in this work (see Figures 2-3).
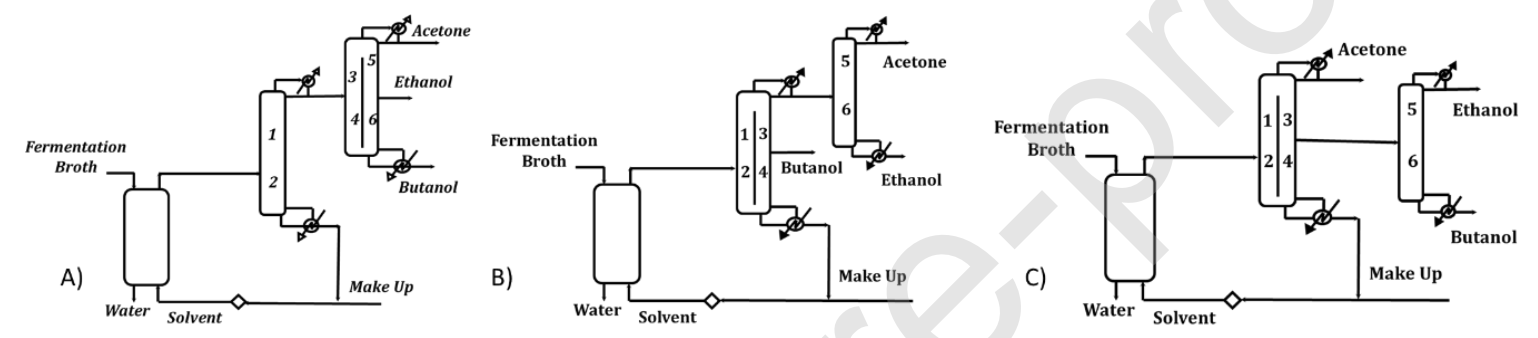

Figure 2. Liquid-liquid extraction-assisted conventional DWC configurations

The complete set of ten schemes are hybrid processes since a liquid-liquid extraction column is included. The inclusion of a liquid-liquid extraction column, with n-hexyl-acetate used as an extraction agent, it breaks both the homogenous and heterogeneous azeotropes (ethanol/water and butanol/water). In general terms, the inclusion of a LLE column promotes energy savings in comparison with conventional schemes (designed exclusively with distillation columns). The first three configurations considered are shown in Figure 2 [18]. This design comprises a liquid-liquid extraction followed by a dividing wall column which performs the ABE separation jointly with extractive purification (DWC); additionally, these configurations are considered as reference configurations for producing the other designs. Considering the designs presented in Figure 2, as the first step, a simple column configuration is selected from the subspace including all the possibilities (location 
of DWC for ABE purification). The selection of a single configuration was carried out based on the performance indices that were evaluated previously [18]. In the second step, a thermally coupled unit is introduced jointly with the elimination of condensers and/or reboilers associated with no-product streams. Instead of heat exchangers, bidirectional thermally coupled vapor and liquid streams are placed (see Figure 4). In the next step, the production of the thermodynamic equivalent schemes from the corresponding original thermally coupled design by rearranging/moving the column sections associated by thermal couplings is considered. Finally, the DWCs are obtained from the thermodynamically equivalent configurations by incorporating the single-column section into its thermally linked column through a dividing-wall. Note that in Figure 4, the stripper section is implemented inside the dividing wall column to produce a DWC scheme with two reboilers is obtained.

Table 1. Feed characterization

\begin{tabular}{ll}
\hline Temperature $(\mathrm{K})$ & 322.039 \\
Vapor fraction & 0 \\
Flowrate $\left(\mathrm{kg} \mathrm{h}^{-1}\right)$ & 45.3592 \\
Composition $(\mathrm{wt} \%)$ & \\
Butanol & 0.3018 \\
Acetone & 0.1695 \\
Ethanol & 0.0073 \\
Water & 0.5214 \\
\hline
\end{tabular}


Journal Pre-proof

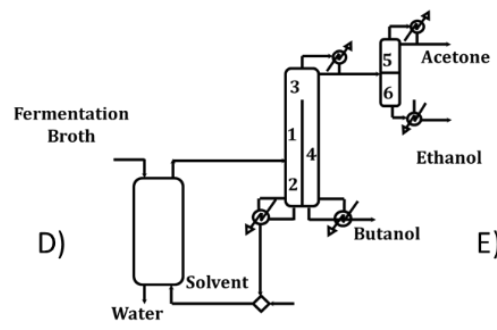

E)

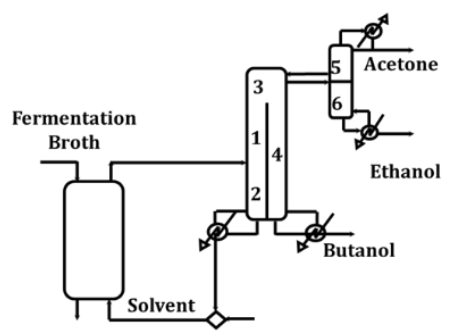

F)
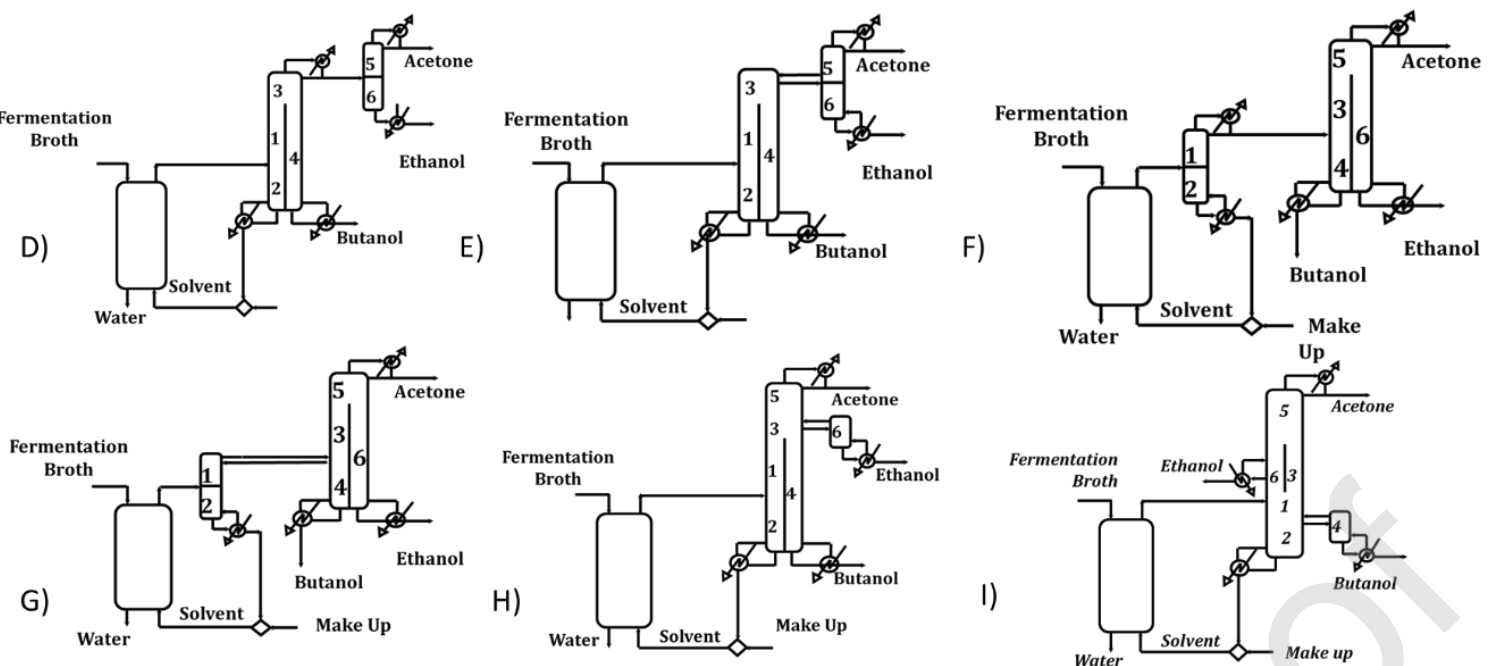

I)

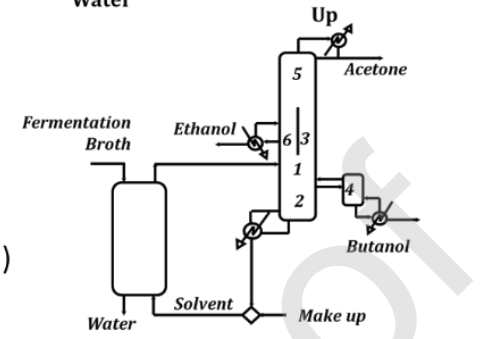

J)

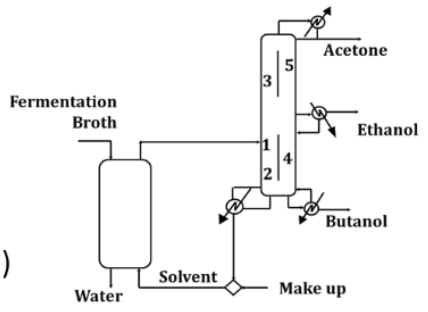

Figure 3. Liquid-liquid extraction-assisted nonconventional DWC configurations

Step 1

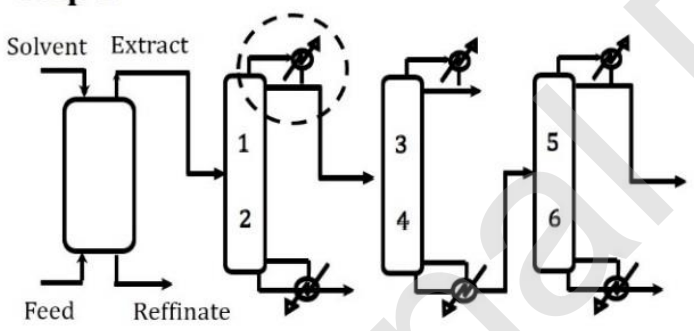

Step 3

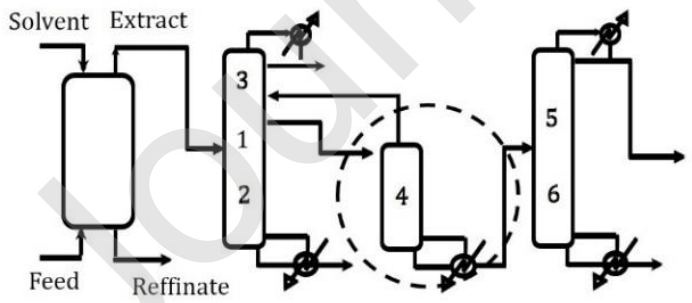

Step 2

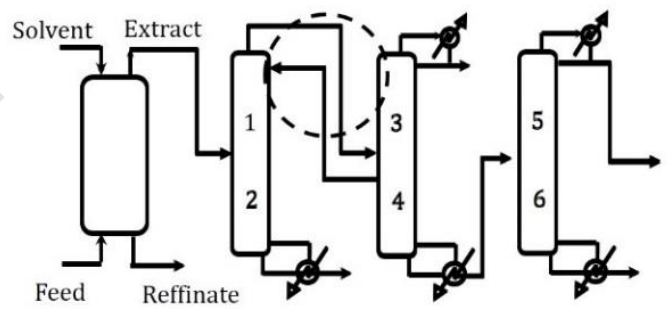

Step 4

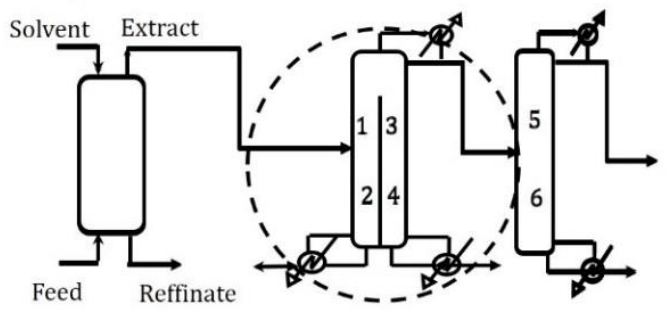

Figure 4. Liquid-liquid extraction-assisted nonconventional DWC configurations synthesis procedure. 


\section{Process Risk Quantification, Green Process Evaluation, and Dynamic Performance}

As it was mentioned previously, earlier studies for biobutanol purification that were carried out focused mostly on both economic and environmental issues, which nowadays are critical issues. However, current political and social demands lead to accomplishing a wider view involving a quite complex perspective for production and separation alternatives. To compare those ten designs, the current analysis was conducted in three parts: a process risk quantification, a green process evaluation, and finally, a control properties test. The purpose for these analyses is to understand the role of those performance indices in the process synthesis procedure. Moreover, it is mandatory to evaluate its role when the process intensification is based on thermal couplings, rearrangement and elimination of column section to provide energy and economic savings.

Initially, the quantitative risk quantification was evaluated by the means of the inherent safety. Regarding risk reduction strategies, if the approached is aimed at reducing accidents or mitigating all the consequences of those accidents, it can be categorized into four elements: inherent, passive, active and procedural.

Inherent and Passive categories are more reliable and robust since they depend on the physicochemical properties of the system rather than the operation and intervention of devices and industrial personnel [36]. In a similar way, inherent safety in some traditional areas of the chemical engineering offer many benefits for safe operation of processes. For example, the research in evaluating catalyst performances commonly leads to improved conversion and yields. Moreover, an additional benefit is the possibility of operating the process at lower pressure and temperature.

Kletz was the first to propose the concept of inherent safety [36]; he defines an inherently safe process if it eliminates or reduces hazards associated with the used materials and 
process operation conditions, and this reduction is a permanent and inseparable part of the process technology [37]. Consequently, with this approach, it will result in safer and more robust process and economically lucrative process operation.

In this work, the risk quantification was evaluated by means of individual risk (IR). The IR is defined as the risk of injury or decease of a person in the neighborhood of a hazard [38]. The main objective of this index is the estimation of affectation caused by the specific incident that occurs with a certain frequency. The mathematical expression for calculating individual risk is the following:

$I R=\sum f_{i} P_{x, y}$

Where $f_{\mathrm{i}}$ is the occurrence frequency of incident $i$, whereas $P_{x, y}$ is the probability of injury or decease caused by the incident $i$. In this work, an irreversible injury (decease) is used, for which more data are recorded. The calculation of IR is carried out through quantitative risk analysis (QRA), which is a methodology used to identify incidents/accidents and their consequences. For distillation columns, the incidents may be both continuous release and instantaneous releases. The frequencies for each incident $\left(f_{i}\right)$ were taken according to the reported information [38]. Figure 5 shows the event tree diagrams obtained with all probabilities of instantaneous and continuous incidents, along with their respective frequencies. Once the incidents have been identified, the probability $P_{x, y}$ can be calculated through a consequence assessment, which consists of determining the physical variables as the thermal radiation, the overpressure and the concentration of the leak originated by incidents and their respective damages. The atmospheric stability type $\mathrm{F}$ is used to calculate the dispersion, which corresponds with a wind speed of $1.5 \mathrm{~m} / \mathrm{s}$ which are the worst scenario possible since low wind speed does not allow a fast dispersion of flammable and 
toxic components, increasing the time of exposure and the probability to begin in contact with an ignition source.

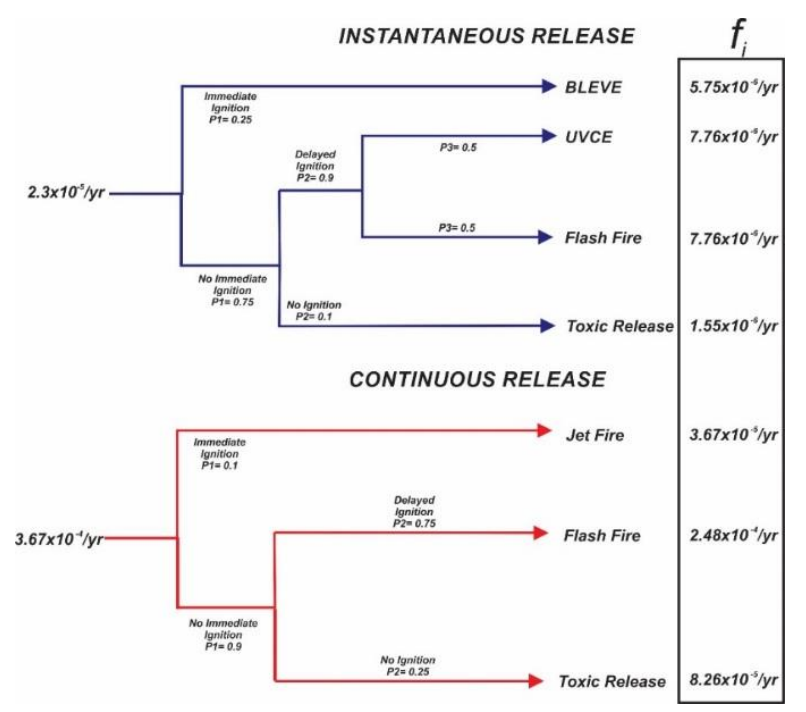

Figure 5. Event tree diagrams for distillation schemes [38]

The probit models associated with diseases/deaths by a certain time of exposure to thermal radiation $[(t e)(E r)]$ and overpressure due to explosions $\left(P^{\circ}\right)$ are given by Eq.2-3. Note both, thermal radiation and overpressure values are directly dependents of UVCE and jet fire calculations. For a detailed explanation please consult Contreras-Zarazua et al. [39]:

$Y=-14.9+2.56 \ln \left[\frac{\left(t_{e}\right)\left(E_{r}^{4 / 3}\right)}{10^{4}}\right]$

$Y=-77.1+6.91 \ln \left(P^{0}\right)$

Due to the lack of reported probit models of toxicity of components considered in this work, the calculation of the damage to toxic releases was carried out using the $\mathrm{LC}_{50}$.

Finally, the probability $P_{x, y}$ is calculated substituting the probit results of the Eq. 2 and Eq. 3 into the following equation:

$P_{x, y}=0.5\left[1+\operatorname{erf}\left(\frac{Y-5}{\sqrt{2}}\right)\right]$ 
Regarding the green process evaluation, Jiménez-González and Constable [23] presented an overview of the main metrics that have been used to test and compare the 'greenness' of processes and products. The interest in using their overview is that it widely covers either separation process or process which involves reactant transformation. Considering the background presented by [23], in this work we considered three green indices to evaluate those purification alternatives in the previous section; the mass intensity, the E-factor, and the greenhouse gas emission.

The mass intensity was initially proposed [40] and is the total amount of mass required to produce a unit of product or service, usually on a wt/wt basis

The mass intensity is defined as follows:

Mass intensity $(M I)=\frac{\text { Total mass used in a process step }(\mathrm{kg})}{\text { Mass of product }(\mathrm{kg})}$

The mass intensity may be used for many processes since it takes yield, stoichiometry, extraction agents and the reagent used in the reaction mixture into account, and expresses this on a weight/weight basis rather than a percentage. Total mass includes everything that is used in a process or processing step with the exception of water. Water has been excluded from mass calculations since it skews mass data in many processes.

The E-factor is the mass ratio of waste to the desired product. Moreover, it can be considered for a process which involves the transformation of products, even atom efficiency may be calculated. The enormity of the waste problem in chemical manufacturing is evident from a consideration of typical E factors of the chemical industry (see Table 2) [41].

Table 2. E factor in some chemical industries

\begin{tabular}{lll} 
Type of Industry & Product tonnage & E factor \\
\hline Oil refining & $10^{6}-10^{8}$ & $<0.1$
\end{tabular}




\begin{tabular}{lll} 
Bulk chemicals & $10^{4}-10^{6}$ & $<1-5$ \\
Fine chemicals & $10^{2}-10^{4}$ & $5-50$ \\
Pharmaceuticals & $10-10^{3}$ & $25-100$ \\
\hline
\end{tabular}

$\boldsymbol{E} \boldsymbol{f a c t o r}=\frac{\text { Total waste }(\mathrm{kg})}{\mathrm{kg} \text { product }}$

The E-factor equals to the amount of waste produced in the process, defined as everything but the desired product. There is only one exclusion, generally, water is excluded from Efactor calculation. As long as E-factor becomes higher means more waste and, consequently, greater negative environmental impact. The utopic E-factor is zero which resembles a zero-waste production.

Another metric to evaluate the greenness of a process is the greenhouse emissions.

Reducing $\mathrm{CO}_{2}$ emissions is an absolute necessity for chemical process industries in order to meet the environmental targets of many international agreements, for example the Paris Accord on climate chnage. Even in previous works, Errico et al. [19] evaluated those designs with an LCA (EI99) method using a Hierarchist perspective (a balanced perspective between short and long term). It is worth studying separately the impact of greenhouse gases on global warming. Note, for example Global Warming Potential (GWP), also referred to as carbon footprint, expresses the amount of greenhouse gases emitted to the atmosphere. Global Warming Potential is a single index that allows relating directly to the amount of greenhouse gas emissions and global warming. GWP seems to have retained its attractiveness and widespread use, mainly because of the simplicity of its definition, the small number of required input parameters and the relative ease of calculation, compared to some of the alternatives [42-44]. 
The case study in this work includes non-conventional distillation columns with an energyintensive profile. Energy consumption in distillation and $\mathrm{CO}_{2}$ gases produced in the atmosphere are strongly related. Therefore, according to the green metrics by JiménezGonzález and Constable (2012), the reduction of CO2 emissions is the main metric for chemical industries. The $\mathrm{CO}_{2}$ emission is calculated as follows [45]:

$\left[\mathrm{CO}_{2}\right]$ emiss $=\left(\frac{Q_{\text {fuel }}}{N H V}\right)\left(\frac{C \%}{100}\right) \alpha$

Where $\alpha=3.67$ is the ratio of molar masses of $\mathrm{CO}_{2}$ and $\mathrm{C}$, while $\mathrm{NHV}(\mathrm{kJ} / \mathrm{kg})$ represents the net heating value of fuel with a carbon content of $\mathrm{C} \%$. In this work, it is assumed that all energy involved in $\mathrm{ABE}$ purification comes from burning $\mathrm{CH}_{4}$ gas. Moreover, the target is to obtain as little as it is possible $\mathrm{CO}_{2}$ emissions.

Furthermore, the control properties of all configurations are analyzed in this work. We used the singular value decomposition technique (SVD) for this purpose. A matrix A $2 \mathrm{C}^{\mathrm{mf}} \mathrm{r}$ (with $\mathrm{r}<\mathrm{m}, \operatorname{rank}(\mathrm{A})=\mathrm{r}$ ), can be represented by its SVD:

$\mathrm{G}=\mathrm{V} \Sigma \mathrm{W}^{\mathrm{H}}$

were $\Sigma=\operatorname{diag}\left(\sigma_{1}, \ldots ., \sigma_{\mathrm{n}}\right), \sigma_{\mathrm{i}}=$ singular value of $\Sigma=\left(\lambda_{\mathrm{i}}\right)^{1 / 2}\left(\mathrm{GG}^{\mathrm{H}}\right) ; \mathrm{V}=\left(\mathrm{v}_{1}, \mathrm{v}_{2}, \ldots ..\right)$, matrix of the left singular vectors, and $\mathrm{W}=(\mathrm{w} 1, \mathrm{w} 2, \ldots .$.$) , the matrix of right singular vectors. The$ interpretation is: linear mapping $\mathrm{y}=\mathrm{Ax}$ can be decomposed as a) compute coefficients of $\mathrm{x}$ along input directions $\mathrm{w}_{\mathrm{i}}$; b) scale coefficients by $\mathrm{v}_{\mathrm{i}}$; c) reconstitute along output directions $\sigma_{I}[46]$. To generate $\mathrm{G}$ for all configuration, first, open-loop dynamic responses to changes in the manipulated variables (in this work $1 \%$ of the nominal value) around the assumed operating point were obtained. For this cases study manipulated variables are reflux ratio, 
reboiler duty and flowrate side stream and the control variables are each composition in the output stream. The responses were obtained using Aspen Dynamics. Transfer function matrices $(\mathrm{G})$ were then collected for each case (Tables 3), and they were subjected to singular value decomposition (SVD). Two parameters of interest are the minimum singular value, $\sigma_{*}$, and the ratio of maximum to minimum singular values, or condition number:

$\gamma=\sigma^{*} / \sigma_{*}$

The minimum singular value is a measure of the invertibility of the system and represents a measure of the potential problems of the system under feedback control. The condition number reflects the sensitivity of the system under uncertainties in process parameters and modeling errors. These parameters provide a qualitative assessment of the theoretical control properties of the alternate designs. The systems with higher minimum singular values and lower condition numbers are expected to show the best dynamic performance under feedback control [47]. In other work, Angelina- Martínez et al. [20] have demonstrated the application of the SVD technique to compare the controllability properties of the intensified separation structures.

\section{Results and discussions}

In this section, the obtained results will be shown along with their discussion. This section will be presented as follows: initially, the safety results are discussed. Next, the green process evaluation, and finally the control results.

Regarding safety analysis evaluated by the individual risk, an initial correlation is found. Observing those schemes named conventional DWC columns, it would be logical to, at first sight, presume that the safer scheme is the one which carries out the separation task with 
the lower heat duty or the lower operating pressure. However, considering the results shown in Table 3 and Figure 6 it would seem contradictory since schemes B (with higher reboiler heat duty) is indeed the safer one from Figure 2. Even though all three schemes performed the same purification, the main difference among those designs lays on the separation carried out by the conventional column. Scheme B) showed the lowest IR value, and this behavior is totally related to the conventional column. According to Figure 2, the conventional column of scheme B) is intentionally designed to separate acetone-ethanol which are the two components in the lower proportion of the $\mathrm{ABE}$ mixture. With this consideration, it is understandable that the IR reduction among the first conventional DWC schemes, since the IR value depends directly from the amount of matter in the separation unit. Note the conventional column in scheme B, is associated with the separation of acetone-ethanol, in consequence, the IR value is considerably smaller.

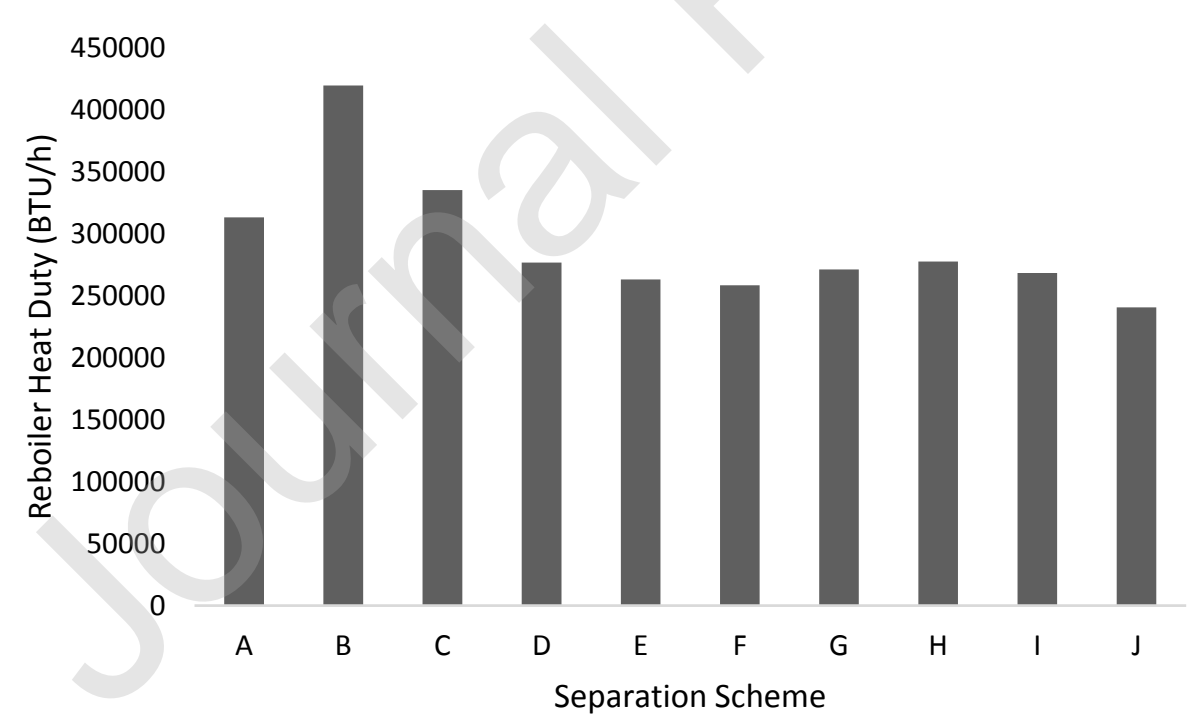

Figure 6. Energy requirements for each separation alternative 
Table 3. Performances Indexes for the cases of study

\begin{tabular}{|c|c|c|c|c|c|c|c|c|c|c|}
\hline $\begin{array}{l}\text { Performance } \\
\text { Indexes }\end{array}$ & $\begin{array}{l}\text { Fig. } 2 \\
\text { a) }\end{array}$ & $\begin{array}{l}\text { Fig } 2 \\
\text { b) }\end{array}$ & $\begin{array}{l}\text { Fig } 2 \\
\text { c) }\end{array}$ & $\begin{array}{l}\text { Fig } \\
\text { 3d) }\end{array}$ & $\begin{array}{l}\text { Fig } \\
\text { 3e) }\end{array}$ & $\begin{array}{l}\text { Fig } \\
\text { 3f) }\end{array}$ & $\begin{array}{l}\text { Fig } \\
\text { 3g) }\end{array}$ & $\begin{array}{l}\text { Fig } \\
\text { 3h) }\end{array}$ & $\begin{array}{l}\text { Fig } \\
\text { 3i) }\end{array}$ & $\begin{array}{l}\text { Fig } \\
\text { 3j) }\end{array}$ \\
\hline $\begin{array}{l}\text { TAC }\left[\mathrm{k} \$ \mathrm{yr}^{-1}\right] \\
\text { (Errico et al. } \\
\text { (2017) }\end{array}$ & 111.86 & 122.99 & 128.45 & 108.54 & 105.57 & 115.5 & 101.78 & 100.85 & 100.59 & 97.88 \\
\hline $\begin{array}{l}\text { EI99 [kpoints yr-1 }] \\
\text { (Errico et al. } \\
\text { (2017) }\end{array}$ & 17.5 & 19.5 & 16.74 & 13.73 & 12.93 & 14.34 & 13.3 & 12.79 & 14.74 & 12.22 \\
\hline IR (Probability/y) & $\begin{array}{l}5.04 \mathrm{E}- \\
04\end{array}$ & $\begin{array}{l}2.56 \mathrm{E}- \\
04\end{array}$ & $\begin{array}{l}5.04 \mathrm{E}- \\
04\end{array}$ & $\begin{array}{l}2.56 \mathrm{E}- \\
04\end{array}$ & $\begin{array}{l}5.04 \mathrm{E}- \\
04\end{array}$ & $\begin{array}{l}2.56 \mathrm{E}- \\
04\end{array}$ & $\begin{array}{l}5.04 \mathrm{E}- \\
04\end{array}$ & $\begin{array}{l}5.04 \mathrm{E}- \\
04\end{array}$ & $\begin{array}{l}5.04 \mathrm{E}- \\
04\end{array}$ & $\begin{array}{l}2.52 \mathrm{E}- \\
04\end{array}$ \\
\hline $\begin{array}{l}\mathrm{CO}_{2} \text { emissions } \\
{[\text { Ton/h] }}\end{array}$ & 0.458 & 0.614 & 0.490 & 0.405 & 0.385 & 0.378 & 0.397 & 0.427 & 0.393 & 0.352 \\
\hline E factor $[\mathrm{kg} / \mathrm{kg}]$ & 8.024 & 8.021 & 8.021 & 8.020 & 8.034 & 8.023 & 8.024 & 8.023 & 8.065 & 8.026 \\
\hline MI $[\mathrm{kg} / \mathrm{kg}]$ & 1.003 & 1.001 & 1.001 & 1.000 & 1.009 & 1.003 & 1.003 & 1.003 & 1.030 & 1.004 \\
\hline
\end{tabular}

Focusing on the non-conventional DWC configurations, again the attention is initially on the heat duty or variable design that may directly affect the IR value. For example, those designs with higher reflux ratio will also generate a higher reboiler heat duty, increasing the IR values. However, all those schemes considered in the case study were previously optimized, with both economic and environmental objective functions. Therefore, during this optimization procedure, a group of designs with several design variables to generate both low economic and environmental impact, named heat reboiler duty, reflux ratio, etc are obtained. This presumption may be corroborated in Table 3-4, even though scheme J) separates the $\mathrm{ABE}$ mixture with lower energy in comparison with the other no-conventional DWC schemes, the difference is not bigger than $15 \%$ among the designs from $\mathrm{D}$ ) to J). From a purely economic point of view (see Table 3), it can be seen that all configuration tested have a TAC which deviated $<30 \%$, with Figure 2 c having the worst economic performance while Figure $2 \mathrm{~g}$ having the best economic performance with respect to the total annualized cost of operations. While this difference is noticeable it is not a sufficiently significant difference. To this end when thinking of process implementation the factor of 
technology readiness level (TRL) comes into effect. Technology readiness level (TRL) metric which was originally developed by NASA can be used to rate how close to implementation of given process technology is [48]. In the context of the alternatives assessed in this work, the process alternative with the least process complexity would have the highest TRL as these alternatives combine two proven technologies. From an economic risk point of view, a process alternative with a higher TRL would have a significantly lower risk of failure during operations as such a risker economic outlook. When considering this TRL based economic risk together with the $<30 \%$ overall deviation in expected cost saving it can be concluded that from a practical implementation point of view, the configuration with the least complexity (hence the higher TRL) would be the best option.

Table 4 shows the main parameters to design schemes 2(e) and 2(g) such as number of stages, reflux ratio, reboiler heat duty, feed stage and interconnection flows between column sections. Considering a column section as a portion of the distillation column not interrupted by entering or existing both mass streams and/or heat flows, Table 4 shows diameters of each section of every schemes. An interesting explanation comes from column diameter; note in Table 4 diameters of section $1+2,4,3+5$ and 6 are given. Diameter $1+2$ represents the diameter of the first column after LLE column, 0.577 meters. On the other hand, the entire diameter of the DWC is 0.5769 meters; however, note that diameter is resulting from the synthesis methodology of joining the section $6(0.288$ meters from a rectifying section in previous synthesis steps) and sections 3,4 and 5 ( 0.288 meters) from a thermodynamic equivalent scheme [18]. So, the sum of both lengths, section 4 (or 3) and 6 is equal to 0.5769 meters and must be interpreted as the distance between the wall inside 
the column and the outer surface of the column. In the same way, Figure $3 e$, section $3+4$ is the sum of $0.288+0.378$ meters.

Table 4 Design and Operating Parameters for the Configurations in Figure 2(g) and 2e

\begin{tabular}{|c|c|c|c|c|c|c|c|c|c|}
\hline & \multicolumn{2}{|l|}{ Fig 3g } & \multicolumn{3}{|c|}{ Columns Section } & \multirow{2}{*}{$\begin{array}{l}\text { Fig } \mathbf{3 e} \\
\text { Extractor }\end{array}$} & \multicolumn{3}{|c|}{ Columns Section } \\
\hline & Extractor & $1+2$ & 4 & $5+3$ & 6 & & $1+2$ & $3+4$ & $5+6$ \\
\hline Number of stages & 5 & 43 & 26 & 71 & 7 & 5 & 43 & 46 & 32 \\
\hline Feed location & --- & 13 & --- & --- & --- & --- & 33 & --- & --- \\
\hline Reflux ratio & --- & --- & --- & --- & --- & --- & & --- & -- \\
\hline Distillate flowrate $\left[\mathrm{kg} \mathrm{h}^{-1}\right]$ & --- & --- & --- & 7.7 & --- & --- & --- & --- & 7.701 \\
\hline Residue flowrate $\left[\mathrm{kg} \mathrm{h}^{-1}\right]$ & --- & 712.1 & 13.6 & --- & 0.3 & --- & 712.1 & 13.6 & 0.316 \\
\hline Liquid split flowrate [ $\left.\mathrm{kg} \mathrm{h}^{-1}\right]$ & --- & 43.4 & 17.3 & --- & 0.42 & --- & 43.4 & 17.38 & --- \\
\hline Extract flowrate $\left[\mathrm{kg} \mathrm{h}^{-1}\right]$ & 733.8 & --- & --- & --- & --- & 733.8 & -- & -- & --- \\
\hline Solvent flowrate $\left[\mathrm{kg} \mathrm{h}^{-1}\right]$ & 712.1 & --- & --- & --- & --- & 712.1 & -- & --- & --- \\
\hline Diameter [m] & 0.335 & 0.577 & 0.288 & 0.577 & 0.288 & 0.335 & 0.288 & 0.666 & 0.299 \\
\hline Pressure [kPa] & 101.3 & 101.3 & 101.3 & 101.3 & 101.3 & 101.3 & 101.3 & 101.3 & 101.3 \\
\hline Condenser duty [kW] & --- & 0 & 0 & 11.233 & 0 & & 0 & 0 & 0 \\
\hline Reboiler duty [kW] & --- & 69.92 & 0.633 & 0 & 0.022 & --- & 64.7 & 3.096 & 1.86 \\
\hline
\end{tabular}

With this in mind, the analysis must be focused in another direction. Note in Table 3 from D) to J), the schemes with the lowest IR values are D) and J). Following the idea of last paragraphs, the Scheme D) performs the separation of acetone-ethanol in a single conventional column, generating a few contributions in comparison with the column to separate butanol, reducing the IR values about 50\%. On the other hand, the main reason for IR reduction in scheme J) is the reduction of equipment. In other words, note that scheme J) performs the entire purification in a single equipment, in this way the risk associated of scheme $\mathrm{J}$ ) is also reduced about $50 \%$, in comparison with those schemes with at least two vessels.

Moreover, an interesting role in the inherent safety lays on the thermal couplings. For example, once a thermal coupling is introduced in scheme D) to produce E) the IR value increases. Nonetheless, starting from F) with a thermal coupling, G) is obtained, in the 
same way despite the relative similarity on its topology, the thermally coupling increase the IR value about $51 \%$.

However, despite scheme $\mathrm{J}$ ) presents the higher number of internal thermal couplings the synthesis methodology allows to obtain equipment with a single shell, which seems to have major importance to reduce the IR value.

Regarding the green metrics, greenhouse gas emissions, E-factor, and Mass Intensity; in light of Table 3, the complete set of ten schemes seems to have a relatively good behavior. Considering the greenhouse gas emissions, it is evident that there is a direct correlation with the reboiler heat duty in Figure 6. Moreover, those ten designs spend little energy in comparison with conventional separation. Therefore, the main correlation on decreasing $\mathrm{CO}_{2}$ emissions is the process intensification. In other words, as long as the process acquires a high level of intensification, it allows reducing energy consumption and the $\mathrm{CO}_{2}$ emission. With this in mind, it is clear that the first three designs A), B) and C) emit the highest amount of $\mathrm{CO}_{2}$, about average $25 \%$ higher than non-conventional DWC schemes. Otherwise, from D) to J) the emissions decrease while reaching the minimum value in the design J), where the highest level of intensification is introduced.

Even that the difference between schemes A)-C) and D)-J) is clear considering the level of intensification, there is also a clear difference among D)-J). In other words, from the scheme D) to J). For example, the scheme $\mathrm{J}$ which we consider as the most intensified since performs the entire separation in a single shell, is the scheme with the lowest $\mathrm{CO}_{2}$ emissions. This difference is totally related to the topology and operative conditions. Clearly, scheme $\mathbf{J}$ ) is designed with lower reflux ratios and the amount vapor/liquid is also lower in comparison with the other intensified alternatives. 
On the other hand, the E-factor presents values close to the values presented for bulk chemicals, all cases the E-factor is almost 8 and the bulk chemicals is 5 (Sheldon, 2007); however, this E-factor is relatively higher in comparison with the oil refining industry, i.e. the theoretical direct competence. The mass intensity values for all cases considered in this study were almost 1, not far away from zero, which is the utopic value [49]. It is interesting to observe how these values are related to the recovery restriction fixed on the optimization procedure as minimal recoveries. In other words, as long as the recovery increase both the E-factor and Mass intensity values will improve. Nevertheless, even if E-factor and MI values increase, will directly affect the $\mathrm{CO}_{2}$ emission. If recovery increase the design variables associated with this target will change. Commonly, if reboiler heat duty increases the recovery rate of the products also increases; however, if the energy consumptions increase also the $\mathrm{CO}_{2}$ emission increases (depending on the energy source and its carbon footprint).

The SVD technique requires transfer function matrices, which are generated by implementing step changes in the manipulated variables of the optimum design of the distillation sequences and registering the dynamic responses of the three products under a open-loop policy. For the distillation sequences presented in this work, four controlled variables were considered, the product mass composition of n-hexyl-acetate, acetone, ethanol and butanol ( $\mathrm{X}_{\mathrm{n} \text {-hexyl-acetate, }} \mathrm{X}_{\text {acetone, }} \mathrm{X}_{\text {ethanol }}$ and $\left.\mathrm{X}_{\text {butanol }}\right)$. Similarly, four manipulated variables were defined, the reflux ratios $(\mathrm{R})$, lateral flow (LF, only in the scheme A) and the heat duties supplied to the reboilers (Q);. After the optimum designs were obtained, openloop dynamic simulations were obtained in Aspen Dynamics in order to obtain the transfer function matrix. Table 5 shows the transfer function matrix generated by using step changes $1 \%$ in the manipulated variables and recording the dynamic behavior of the four product 
mass compositions $\left(\mathrm{X}_{\mathrm{n} \text {-hexyl-acetate }}, \mathrm{X}_{\text {acetone }}, \mathrm{X}_{\mathrm{ethanol}}\right.$ and $\left.\mathrm{X}_{\text {butanol }}\right)$. The transfer function matrix shown in Table 5 corresponds to the arrangement $\mathrm{J}$. It can be noted that the dynamic responses can be adjusted in general to first order models. Similar transfer function matrix can be obtained for other schemes.

Figure 7 presents the minimum singular value. For this case study the configurations $G$ ) and A) show the highest value of $\sigma^{*}$. The results indicate that configurations that present two interconnecting thermal links in top or bottom or a DWC as last equipment will show better dynamic behavior. It can be expected that those options will present better closedloop dynamic behavior for both set-point tracking and load rejection in comparison to other distillation sequences being studied. On the other hand, sequences I) and D) show the lowest minimum singular value. At low frequencies A), D) and J) showed the lowest condition number and highest minimum singular value. These results indicate that arrangements with only one interconnecting thermal linking or thermal links in side stream will present the worst control properties.

Table 5. Matrix of transfer functions for case $\mathbf{J}$ ).

\begin{tabular}{|l|c|c|c|c|}
\hline & $\mathbf{Q}_{1}(\mathbf{K W})$ & $\mathbf{Q}_{2}(\mathbf{K W})$ & $\mathbf{Q}_{3}(\mathbf{K W})$ & $\mathbf{R}(\mathbf{m o l} / \mathbf{m o l})$ \\
\hline $\left.\mathrm{X}_{\text {Hexyl acetate }} \% \mathrm{w} / \mathrm{w}\right)$ & $\frac{-0.3836}{1+2.73 \mathrm{~s}}$ & $\frac{-0.004}{1+2687.63 \mathrm{~s}}$ & $\frac{-0.0004}{1+61.2917 \mathrm{~s}}$ & $\frac{-0.0604}{1+1.518 \mathrm{~s}}$ \\
\hline $\mathrm{X}_{\text {butanol }(\% \mathrm{w} / \mathrm{w})}$ & $\frac{2.1574}{1+0.3522 \mathrm{~s}}$ & $\frac{0.008}{1+6745.96 \mathrm{~s}}$ & $\frac{0.0052}{1+54.16 \mathrm{~s}}$ & $\frac{-0.06}{1+1.64 \mathrm{~s}}$ \\
\hline $\mathrm{X}_{\text {ethanol }(\% \mathrm{w} / \mathrm{w})}$ & $\frac{0.6370}{1+127.845 \mathrm{~s}}$ & $\frac{-0.0164}{1+49.53 \mathrm{~s}}$ & $\frac{0.0064}{1+92.62 \mathrm{~s}}$ & $\frac{-0.1128}{1+20.8137 \mathrm{~s}}$ \\
\hline $\left.\mathrm{X}_{\text {Acetone }} \% \mathrm{w} / \mathrm{w}\right)$ & $\frac{0.0001}{1+1.174 \mathrm{~s}}+\frac{0.67}{1+13.98 \mathrm{~s}}$ & $\frac{-0.0024}{1+43.4693 \mathrm{~s}}$ & $\frac{-0.0092}{1+43.59 \mathrm{~s}}$ & $\frac{-0.0024}{1+1.4356 \mathrm{~s}}$ \\
\hline
\end{tabular}




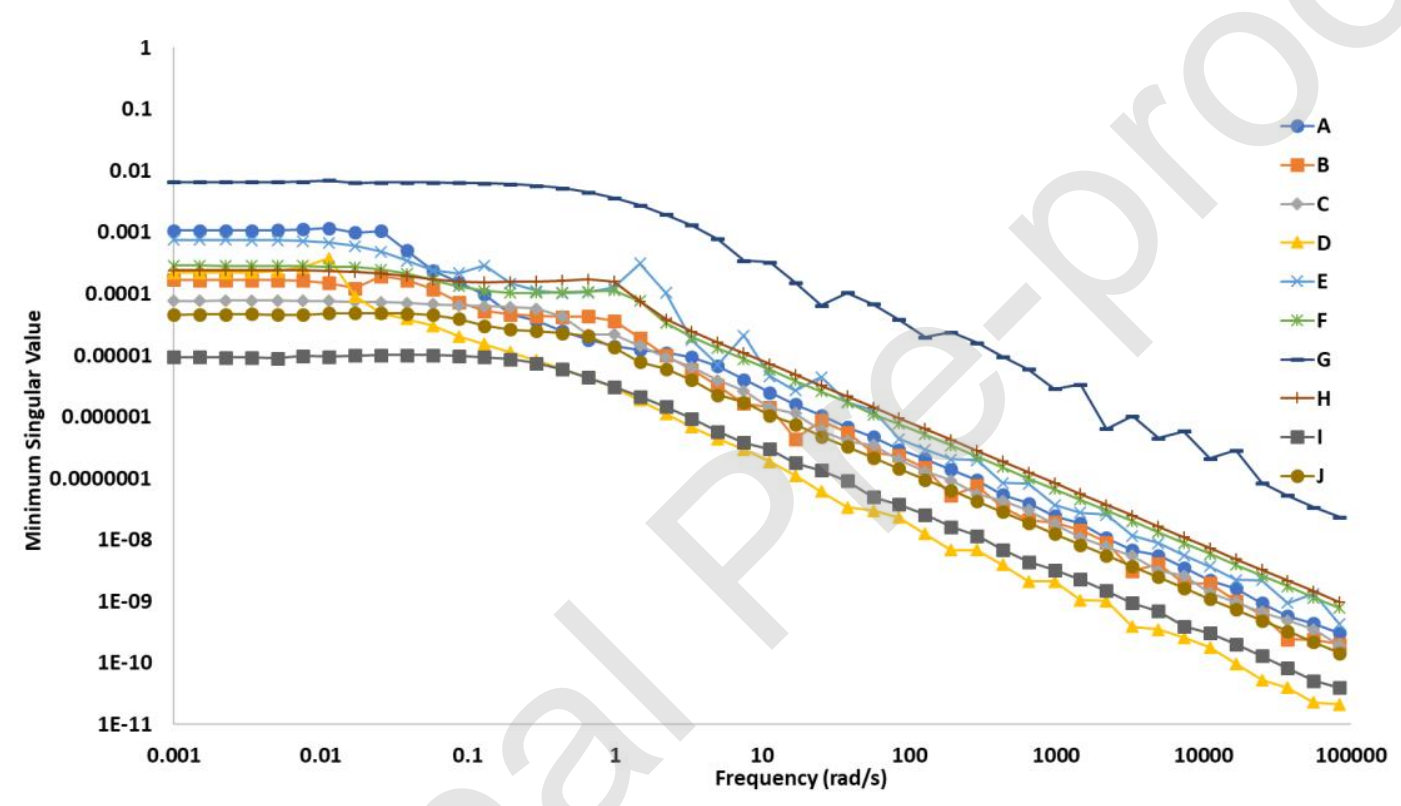

Figure 7. Minimum Singular Value for the cases of study.

The condition number is displayed in Figure 8. Similar control results to minimum singular value are shown: sequences with two interconnecting links in top or bottom or a DWC as last equipment display good dynamic behavior. From a physical point of view, low values of the minimum singular value and high values of the condition number imply large movements in the control valves for changes in the set-points and load rejection. Segovia- 
Hernández et al., (2002) remark that the control in a side stream, in intensified separation configurations, present problems in dynamic behavior. This is perhaps because of its inverse response behavior under open-loop operation. Tamayo-Galván et al. [51] indicate that a reduction in the number of interconnections, in intensified separation systems does not necessarily provide the operational advantages. It is apparent that the presence of recycle streams, instead of deteriorating the dynamic behavior of separation sequences, may contribute positively to their dynamic properties. Also Lucero- Robles et al. [52] have shown that the DWC located at the end of the sequence can show good control properties. Therefore, the results generated in this work are consistent with those previously reported in the literature.

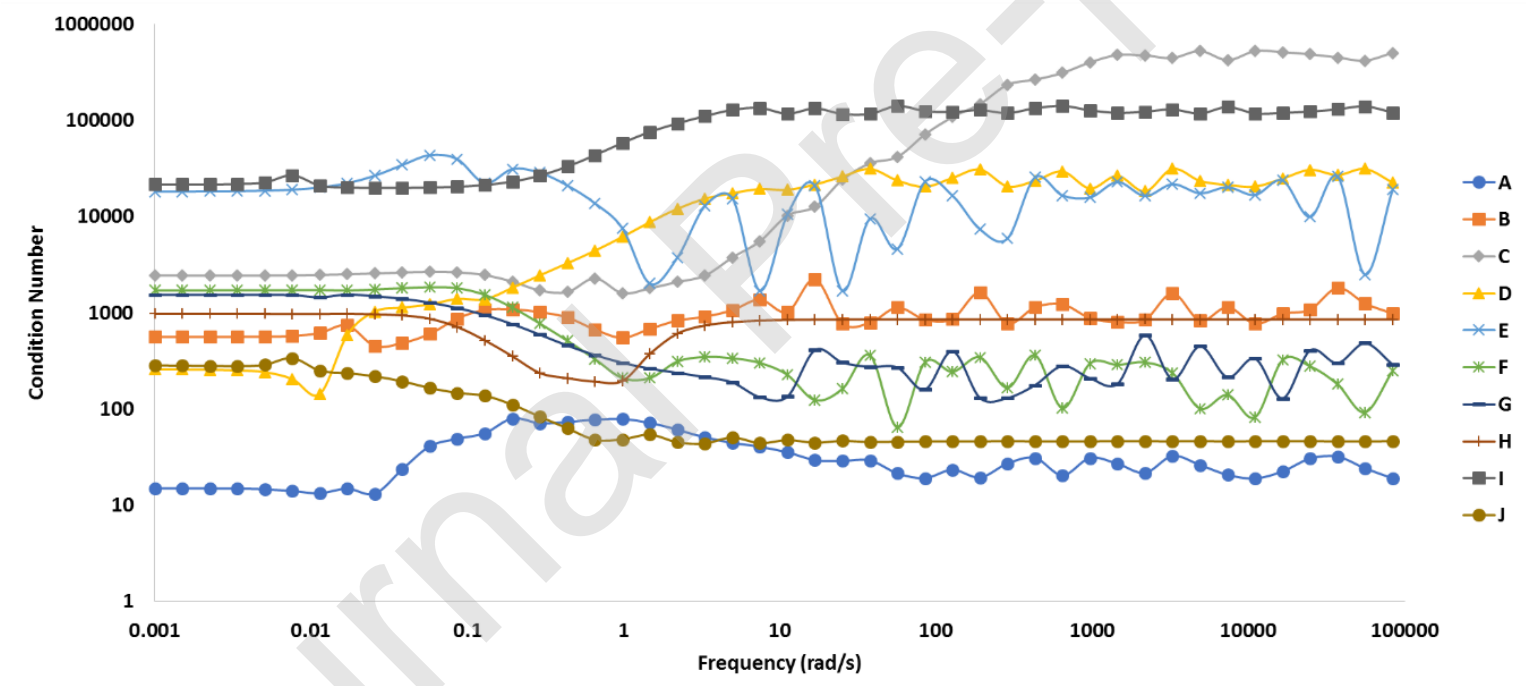

Figure 8. Condition number for the cases of study

As preliminary conclusions, it is clear that as long the level of intensification increases the inherent risk measured by individual risk, decrease. In other words, the most intensified process shows better values of IR in comparison with the less intensified process. Moreover, combining unit operations and separation tasks is associated with a reduction in energy demands and low greenhouse gas emissions. The green process evaluation showed 
that the complete set of alternatives exhibited relatively good values, with an E-factor of 8, near the common values for bulks in chemical industries. Regarding the Mass Intensity, the average values were about 1 , not so far from the utopic point of zero.

On the other hand, when the dynamic properties were evaluated, good dynamic behavior is totally associated with the number of thermal couplings. In other words, as long as the scheme becomes more intensified the dynamic properties may improve. This correlation intensification/dynamic properties have been previously studied in many similar cases where the dynamic properties of intensified designs are studied. For example, the works published by Gomez-Castro et al. [53] concluded that the dividing wall columns may present better control properties in comparison with its conventional equivalent; in the same sense Sánchez-Ramírez et al. [21] concluded that for bio-butanol separation, the intensified process, involving distillation columns with side stream is better conditioned than less complex systems. Note however, the scheme with the highest level of intensification did not show the best control properties in all range of frequency. Only at low frequencies, a relatively good dynamic behavior may be observed; in operational terms it may indicate a well-conditioned process under low disturbances. In future, systematic economic and sustainable assessment of control structures will be beneficial for an in-depth understanding of the ways to overcome the challenges associated with control and operation of highly intensified unit operations [54].

\section{Conclusions}

In this work, the inherent risk, the green process evaluation, and the control properties were tested to a set of 10 hybrid designs, designed with an LLE extraction column and distillation columns, including at least one DWC for bio-butanol purification. The 
evaluated schemes were separated into two groups named conventional DWC and nonconventional DWC columns. A previous work [18], reported a reduction of about $22 \%$ of the TAC and $18 \%$ of an environmental index for the alternatives with the highest level of intensification (I and J). In this work, regarding inherent risk, a tendency was observed, to separate acetone-ethanol in a single column will produce a lower effect on IR value in comparison with other separations since the pair acetone-ethanol represents the lowest amount of matter in a classical ABE mixture. In brief, to perform this separation in a single column reduce the IR value about 50\%. In the same way, to reach a high level of intensification also allows improving the IR value. For example, the scheme J), were the entire $\mathrm{ABE}$ purification is performed in a single shell, showed a reduction of about $50 \%$ in comparison with the other separation schemes. Besides, a tendency between thermally couplings and IR values was observed, the substitution of a single stream for a thermally coupling increase the IR values.

According to green metrics results, the $\mathrm{CO}_{2}$ emissions, a similar trend is observed, as long as the intensification level increase, the energy invested reduce jointly the $\mathrm{CO}_{2}$ emissions. Moreover, the complete set of separation alternatives showed relatively good values of $\mathrm{E}$ factor and Mass Intensity in comparison with current chemical industries. However, in order to increase those green metrics and improve its values, it is necessary to reduce wasted materials on each alternative. Evidently, the reduction is probably accompanied by energy requirements, which probably results in $\mathrm{CO}_{2}$ increasing, so it would be interesting to reach and find a middle point for all the green metrics.

The control properties study showed marked trends regarding the thermal couplings, a reduction in the number of interconnections, in intensified separation systems does not necessarily provide the operational advantages originally expected given the resulting, 
simpler, structural design. Apparently, the presence of recycle streams, instead of deteriorating the dynamic behavior of separation sequences, may contribute positively to their dynamic properties.

In general terms, the scheme with a high level of intensification showed relatively good dynamic properties at low frequencies. However, the scheme with the highest level of intensification (scheme J), even though at low frequencies presents relatively good dynamic behavior, is not actually the best one. In other words, as long as the high level of intensification is reached, not always the best dynamic properties may be obtained, a similar conclusion is obtained in the application of intensification techniques applied to ethanol purification [55]. Nevertheless, the scheme J), is competitive regarding IR, green metrics, and dynamic properties in comparison with the other alternatives. In this manner, as long as the process increases its level of intensification for bio-butanol purification, also increase their green properties. In other words, the intensified downstream process is able to improve almost all green metrics in order to be a more sustainable process. It is well-known that the entire process to produce biobutanol depends on several previous factors, however, this work shows that this kind of intensified process possess many green metrics if the intention is to be fitted in an entire process under the same trend/approach for further direct comparison with the traditional process to obtain butanol. 


\section{References}

[1] N. Qureshi, T. Ezeji, Butanol, ‘a superior biofuel' production from agricultural residues (renewable biomass): recent progress in technology, Biofuels, Bioproductos and Biorefining. (2008) 319-330. doi:10.1002/bbb.

[2] V. V. Zverlov, O. Berezina, G.A. Velikodvorskaya, W.H. Schwarz, Bacterial acetone and butanol production by industrial fermentation in the Soviet Union: Use of hydrolyzed agricultural waste for biorefinery, Applied Microbiology and Biotechnology. 71 (2006) 587-597. doi:10.1007/s00253-006-0445-z.

[3] N. Qureshi, B.C. Saha, B. Dien, R.E. Hector, M. a. Cotta, Production of butanol (a biofuel) from agricultural residues: Part I - Use of barley straw hydrolysate, Biomass and Bioenergy. 34 (2010) 559-565. doi:10.1016/j.biombioe.2009.12.024.

[4] P. Dürre, Fermentative production of butanol--the academic perspective., Current Opinion in Biotechnology. 22 (2011) 331-6. doi:10.1016/j.copbio.2011.04.010.

[5] C.L. Gabriel, Butanol Fermentation Process, Industrial and Engineering Chemistry. 20 (1928) 1063-1067. doi:10.1021/ie50226a020.

[6] T.C. Ezeji, N. Qureshi, H.P. Blaschek, Production of acetone butanol (AB) from liquefied corn starch, a commercial substrate, using Clostridium beijerinckii coupled with product recovery by gas stripping, Journal of Industrial Microbiology and Biotechnology. 34 (2007) 771-777. doi:10.1007/s10295-007-0253-1.

[7] A.A. Kiss, S.J. Flores, C.A. Infante, Towards energy efficient distillation technologies e Making the right choice, Energy. 47 (2012) 531-542. doi:10.1016/j.energy.2012.09.038.

[8] E. Sánchez-Ramírez, J.J. Quiroz-Ramírez, J.G. Segovia-Hernández, S. Hernández, 
J.M. Ponce-Ortega, Economic and environmental optimization of the biobutanol purification process, Clean Technologies and Environmental Policy. 18 (2015) 395411. doi:10.1007/s10098-015-1024-8.

[9] E.A. Wolff, S. Skogestad, Operation of Integrated Three-Product (Petlyuk) Distillation Columns, Industrial \& Engineering Chemistry Research. (1995) 20942103. doi:10.1021/ie00045a018.

[10] M.I.A. Mutalib, R.S. Fellow, Operation and Control of Dividing Wall Part 1: Degrees of Freedom and Dynamic Simulation, Trans IChemE. 76 (1998). doi:10.1205/026387698524956.

[11] J.G. Segovia-hern, S. Hern, A. Jim, Analysis of dynamic properties of alternative sequences to the Petlyuk column, Computers and Chemical Engineering. 29 (2005) 1389-1399. doi:10.1016/j.compchemeng.2005.02.027.

[12] K.A. Amminudin, R. Smith, D.Y. Thong, G.P. Towler, Design and Optimization of Fully Thermally Part 1 : Preliminary Design and Optimization Methodology, Trans IChemE. 79 (2001). doi:10.1205/026387601753192028.

[13] D. Schultz, M.A., Stewart, D.G., Harris, J.M., Rosenblum, S.P., Shakur, M.S., O'Brien, Reduce Costs with Dividing Wall Columns, CEP Magazine. (2002).

[14] A.A. Kiss, Distillation technology - still young and full of breakthrough opportunities, Journal of Chemical Technology and Biotechnology. 89 (2014) 479498. doi:10.1002/jctb.4262.

[15] O.Z. Dejanovic I, Matijasevic L, Dividing wall column — A breakthrough towards sustainable distilling, Chemical Engineering and Processing: Process Intensification. 49 (2010) 559-580. doi:10.1016/j.cep.2010.04.001.

[16] E. Sánchez-Ramírez, J.J. Quiroz-Ramírez, S. Hernández, J.G. Segovia-Hernández, 
A.A. Kiss, Optimal hybrid separations for intensified downstream processing of biobutanol, Separation and Purification Technology. 185 (2017) 149-159. doi:10.1016/j.seppur.2017.05.011.

[17] C.O. Okoli, T.A. Adams, Design of dividing wall columns for butanol recovery in a thermochemical biomass to butanol process, Chemical Engineering and Processing: Process Intensification. 95 (2015) 302-316. doi:10.1016/j.cep.2015.07.002.

[18] M. Errico, E. Sanchez-Ramirez, J.J. Quiroz-Ramìrez, B.G. Rong, J.G. SegoviaHernandez, Multiobjective Optimal Acetone-Butanol-Ethanol Separation Systems Using Liquid-Liquid Extraction-Assisted Divided Wall Columns, Industrial and Engineering Chemistry Research. 56 (2017) 11575-11583. doi:10.1021/acs.iecr.7b03078.

[19] W.L. Luyben, Control of the Heterogeneous Azeotropic n -Butanol/Water Distillation System, Energy \& Fuels. (2008) 4249-4258. doi:10.1021/ef8004064.

[20] A.Y. Angelina-Martínez, E. Sánchez-Ramírez, J.J. Quiroz-Ramírez, J.G. SegoviaHernández, Controllability Analysis of Process Alternatives for Biobutanol Purification, Chemical Engineering and Technology. 38 (2015) 1591-1598. doi:10.1002/ceat.201500103.

[21] E. Sánchez-Ramírez, H. Alcocer-García, J.J. Quiroz-Ramírez, C. Ramírez-Márquez, J.G. Segovia-Hernández, S. Hernández, M. Errico, A.J. Castro-Montoya, Control properties of hybrid distillation processes for the separation of biobutanol, Journal of Chemical Technology and Biotechnology. 92 (2017) 959-970. doi:10.1002/jctb.5020.

[22] D.J.C. Constable, D. Curzons, V.L. Cunningham, Metrics to ' green ' chemistry which are the best? Green Context, (2002) 521-527. doi:10.1039/b206169b. 
[23] C. Jiménez-González, D.J.C. Constable, C.S. Ponder, Evaluating the "greenness" of chemical processes and products in the pharmaceutical industry - A green metrics primer, Chemical Society Reviews. 41 (2012) 1485-1498. doi:10.1039/c1cs15215g.

[24] J.M. Ponce-Ortega, M.M. Al-Thubaiti, M.M. El-Halwagi, Process intensification: New understanding and systematic approach, Chemical Engineering and Processing: Process Intensification. 53 (2012) 63-75. doi:10.1016/j.cep.2011.12.010.

[25] P. Lutze, R. Gani, J.M. Woodley, Process intensification: A perspective on process synthesis, Chemical Engineering and Processing: Process Intensification. 49 (2010) 547-558. doi:10.1016/j.cep.2010.05.002.

[26] C. Ramshaw, G. Chemistry, Process Intensification and Green Chemistry, Green Chemistry. (1999) 15-17. doi:10.1039/GC990G15.

[27] B.B. Andersen, R.F. Nielsen, I.A. Udugama, E. Papadakis, K. V. Gernaey, J.K. Huusom, S.S. Mansouri, J. Abildskov, Integrated Process Design and Control of Cyclic Distillation Columns Integrated Process Design and Control of Cyclic Distillation Columns Integrated Process Design and Control of Cyclic Distillation Columns Integrated Process Design and Control of Cyclic, IFAC-PapersOnLine. 51 (n.d.) 542-547. doi:10.1016/j.ifacol.2018.09.368.

[28] S.S. Mansouri, J.K. Huusom, R. Gani, K. Lyngby, M. Sales-cruz, Systematic Integrated Process Design and Control of Binary Element Reactive Distillation Processes, AIChe. 00 (2016). doi:10.1002/aic.

[29] S.S. Mansouri, M. Sales-cruz, J.K. Huusom, R. Gani, Systematic Integrated Process Design and Control of Reactive Distillation Processes Involving Multi-elements, Chemical Engineering Research and Design. (2016). doi:10.1016/j.cherd.2016.07.010. 
[30] M. Lee, L. Tsai, G. Hong, H. Lin, Multiphase equilibria for binary and ternary mixtures containing propionic acid, $\mathrm{n}$-butanol, butyl propionate, and water, Fluid Phase Equilibria. 216 (2004) 219-228. doi:10.1016/j.fluid.2003.09.009.

[31] K. Kraemer, A. Harwardt, R. Bronneberg, W. Marquardt, Separation of butanol from acetone-butanol-ethanol fermentation by a hybrid extraction-distillation process, Computers \& Chemical Engineering. 35 (2011) 949-963. doi:10.1016/j.compchemeng.2011.01.028.

[32] I. Patraşcu, C.S. Bîldea, A.A. Kiss, Eco-efficient butanol separation in the ABE fermentation process, Separation and Purification Technology. 177 (2017) 49-61. doi:10.1016/j.seppur.2016.12.008.

[33] A.A. Kiss, Novel applications of dividing-wall column technology to biofuel production processes, Journal of Chemical Technology and Biotechnology. 88 (2013) 1387-1404. doi:10.1002/jctb.4108.

[34] H. Kosuge, K. Iwakabe, Estimation of isobaric vapor - liquid - liquid equilibria for partially miscible mixture of ternary system, Fluid Phase Equilibria. 233 (2005) 4755. doi:10.1016/j.fluid.2005.04.010.

[35] R. Goedkoop, M., \& Spriensma, Eco-indicator 99 Manual for Designers, PRe' Consultants, Amersfoort, The Netherlands. (2000).

[36] F.I. Khan, P.R. Amyotte, How to Make Inherent Safety Practice a Reality, The Canadian Journal of Chemical Engineering. 81 (2003) 2-16. doi:10.1002/cjce.5450810101.

[37] K. Trevor, Learning from Accidents, Gulf Professional Publishing, 2001.

[38] R.A. Freeman, CCPS guidelines for chemical process quantitative risk analysis, Plant/Operations Progress. 9 (1990) 231-235. doi:10.1002/prsb.720090409. 
[39] G. Contreras-Zarazua, E. Sánchez-Ramírez, J.A. Vazquez-Castillo, J.M. PonceOrtega, M. Errico, A.A. Kiss, J.G. Segovia-Hernández, Inherently Safer Design and Optimization of Intensified Separation Processes for Furfural Production, Industrial \& Engineering Chemistry Research. (2019). doi:10.1021/acs.iecr.8b03646.

[40] A.D. Curzons, D.J.C. Constable, D.N. Mortimer, V.L. Cunningham, So you think your process is green, how do you know? - Using principles of sustainability to determine what is green - A corporate perspective, Green Chemistry. 3 (2001) 1-6. doi:10.1039/b007871i.

[41] R.A. Sheldon, The e Factor: Fifteen years on, Green Chemistry. 9 (2007) 12731283. doi:10.1039/b713736m.

[42] A.R. Mosier, A.D. Halvorson, C.A. Reule, X.J. Liu, Net Global Warming Potential and Greenhouse Gas Intensity in Irrigated Cropping Systems in Northeastern Colorado, Journal of Environment Quality. 35 (2006) 1584. doi:10.2134/jeq2005.0232.

[43] D.A. Lashof, D.R. Ahuja, Relative contributions of greenhouse gas, Nature. 344 (2002) 529-531. doi:10.1038/344529a0.

[44] K.P. Shine, J.S. Fuglestvedt, K. Hailemariam, N. Stuber, Alternatives to the Global Warming Potential for Comparing Climate Impacts of Emissions of Greenhouse Gases, Climate Change. 68 (2005) 281-302.

[45] M.A. Gadalla, Z. Olujic, P.J. Jansens, M. Jobson, R. Smith, Reducing CO2 emissions and energy consumption of heat-integrated distillation systems, Environmental Science and Technology. 39 (2005) 6860-6870. doi:10.1021/es049795q.

[46] W.K. Häggblom K, Control Structures, Consistency, and Transformations, First, 
Springer, NY, 1992. doi:10.1007/978-1-4757-0277-4_10.

[47] W.L. Luyben, C.-C. Yu, Reactive Distillation Design and Control, John Wiley \& Sons, Inc., Hoboken, NJ, USA, 2008. doi:10.1002/9780470377741.

[48] Technology Readiness Level, NASA. (2012).

[49] D.J.C. Constable, A.D. Curzons, V.L. Cunningham, Metrics to "green" chemistry Which are the best?, Green Chemistry. 4 (2002) 521-527. doi:10.1039/b206169b.

[50] J.G. Segovia-Hernández, S. Hernández, A. Jiménez, Control behaviour of thermally coupled distillation sequences, Chemical Engineering Research and Design. 80 (2002) 783-789. doi:10.1205/026387602320776858.

[51] V.E. Tamayo-Galván, J.G. Segovia-Hernández, S. Hernández, Controllability analysis of alternate schemes to complex column arrangements with thermal coupling for the separation of ternary mixtures, Computers and Chemical Engineering. 32 (2008) 3057-3066. doi:10.1016/j.compchemeng.2008.04.007.

[52] E. Lucero-Robles, F.I. Gómez-Castro, C. Ramírez-Márquez, J.G. SegoviaHernández, Petlyuk Columns in Multicomponent Distillation Trains: Effect of Their Location on the Separation of Hydrocarbon Mixtures, Chemical Engineering \& Technology. (2016). doi:10.1002/ceat.201600152.

[53] F.I. et al. Gómez-Castro, Dividing Wall Distillation Columns : Optimization and Control Properties, Chemical Engineering \& Technology. (2008) 1246-1260. doi:10.1002/ceat.200800116.

[54] I.A. Udugama, M.A. Taube, S.S. Mansouri, R. Kirkpatrick, K. V Gernaey, W. Yu, B.R. Young, A Systematic Methodology for Comprehensive Economic Assessment of Process Control Structures, Industrial \& Engineering Chemistry Research. (2018). doi:10.1021/acs.iecr.8b01883. 
[55] C.E. Torres-ortega, C. Ramírez-márquez, E. Sánchez-ramírez, J.J. Quiroz-ramírez, J.G. Segovia-hernandez, B. Rong, Effects of intensification on process features and control properties of lignocellulosic bioethanol separation and dehydration systems, Chemical Engineering \& Processing: Process Intensification. 128 (2018) 188-198. doi:10.1016/j.cep.2018.04.031. 